\title{
SUBSTRATOS NO ENRAIZAMENTO DE ESTACAS HERBÁCEAS DE FIGUEIRA ORIUNDAS DA DESBROTA
}

\author{
Substrates in the rooting of fig tree herbaceous cuttings originated from the sprouting
}

\author{
Rafael Pio ${ }^{1}$, João Paulo Campos de Araújo ${ }^{2}$, Débora Costa Bastos ${ }^{2}$, André Siqueira Rodrigues Alves ${ }^{3}$, \\ Fábio Albuquerque Entelmann ${ }^{3}$, João Alexio Scarpare Filho ${ }^{4}$, Francisco de Assis Alves Mourão Filho ${ }^{4}$
}

\section{RESUMO}

Com o presente trabalho teve-se como objetivo verificar o enraizamento de estacas de figueira oriundas da desbrota, por meio da utilização de diferentes substratos. Foram coletadas estacas herbáceas de figueira 'Roxo de valinhos', aproximadamente com $10 \mathrm{~cm}$ de comprimento, no momento da desbrota da figueira. As estacas com apenas duas folhas e sem gema apical foram acondicionadas em bandejas de polipropileno, contendo diferentes substratos: casca de pinus ${ }^{\circledR}$, vermiculita ${ }^{\circledR}$, fibra de $\operatorname{coco}^{\circledR}$, plantmax ${ }^{\circledR}$, solo + esterco bovino $(1: 1 \mathrm{v} / \mathrm{v})$ e tropstrato ${ }^{\circledR}$. Posteriormente, as estacas foram colocadas em casa-devegetação, com umidade e temperatura controlada. Após 50 dias, avaliaram-se a porcentagem de estacas enraizadas, brotadas e mortas, número de folhas e raízes emitidas da estaca. Os substratos fibra de coco ${ }^{\circledR}$ e plantmax ${ }^{\circledR}$ promoveram melhores resultados.

Termos para indexação: Ficus carica L., propagação e estaquia.

\section{ABSTRACT}

The present work had the objective to verify the rooting of fig tree cuttings originating from sprouting, through the use of different substrates. Herbaceous cuttings were collected of 'Roxo de valinhos' fig tree with $10 \mathrm{~cm}$ of length when the sprouting was happening. The cuttings with two leaves and not of the apical bud to conditioned in polypropylene trays containing different substrates: casca de pinus ${ }^{\circledR}$, vermiculita ${ }^{\circledR}$, coconut fiber ${ }^{\circledR}$, plantmax ${ }^{\circledR}$, soil + cow mature $(1: 1 \mathrm{v} / \mathrm{v})$ and tropstrato $^{\circledR}$. The cuttings were placed at greenhouse, under humidity and temperature control. After 50 days, the rooting, sprouting and death cutting percentage, the number of leaves and roots of each cutting were evaluated. The substrates coconut fiber $^{\circledR}$ and plantmax ${ }^{\circledR}$ promoted better results.

Index terms: Ficus carica L., propagation and cutting.

(Recebido para publicação em 11 junho de 2004 e aprovado em 8 de abril de 2005)

\section{INTRODUÇÃO}

A figueira (Ficus carica L.) é cultivada no Brasil principalmente nas Regiões Sul e Sudeste, devido às condições climáticas de invernos suaves e verões quentes ou relativamente suaves e úmidos, o que favorece o melhor potencial de produção da ficicultura (CHALFUN et al., 1997). A cultivar Roxo de valinhos constitui-se praticamente na única cultivar utilizada comercialmente, caracterizada pelo seu elevado vigor e produtividade (PENTEADO, 1999). No Estado de São Paulo, a figueira constitui-se em uma importante frutífera cultivada, destacando-se com cerca de 840 mil pés em cultivo, com uma produção média nas últimas cinco safras de 9.685 ton, e na região de Valinhos concentram-se mais de $80 \%$ da produção paulista de figo (ANUÁRIO..., 2002). Já no Estado de Minas Gerais, toda a produção está voltada à obtenção de figos verdes para a indústria (COELHO et al., 2002).

Entre os diferentes aspectos que envolvem a cultura da figueira, destaca-se a implantação do pomar. No processo propagativo da figueira, a estaquia é o principal método utilizado, sendo o material oriundo da poda hibernal (julho-setembro) aproveitado na propagação e formação de novos figueirais, utilizando-se apenas as estacas caulinares dotadas de 1,5-3 cm de diâmetro e 30-40 cm de comprimento, colocadas verticalmente na cova de plantio no mesmo período referente a sua coleta (CHALFUN \& HOFFMANN, 1997).

1. Engenheiro Agrônomo, Dr., Pesquisador Científico Centro APTA Frutas - Instituto Agronômico de Campinas/IAC - Av. Luiz Pereira dos Santos, no 1500 - Corrupira - 13214-820 - Jundiaí, SP.

2. Engenheiro Agrônomo, M.Sc., Doutorando do curso de Fitotecnia - Departamento de Produção Vegetal - Universidade de São Paulo Escola Superior de Agricultura "Luiz de Queiroz" - USP/ESALQ - Piracicaba, SP.

3. Graduando do curso de Agronomia, Universidade de São Paulo, Escola Superior de Agricultura "Luiz de Queiroz" - USP/ESALQ, Piracicaba, SP Bolsista de I.C. do CNPq.

4. Engenheiro Agrônomo, Dr., Professor do Departamento de Produção Vegetal - Universidade de São Paulo - Escola Superior Agricultura "Luiz de Queiroz" - USP/ESALQ - Piracicaba, SP. 
Devido a não-coincidência do plantio das estacas com o período chuvoso na Região Sudeste, essa técnica propicia um baixo índice de vingamento, havendo a necessidade da utilização de duas estacas por cova, assegurando-se, assim, um enraizamento na ordem de $60 \%$, o que acarreta um plantio desuniforme e com a necessidade de replantios (GONÇALVES, 2002).

Uma variante na propagação da figueira é o enraizamento das estacas previamente em ambiente controlado, podendo utilizar estacas de menor diâmetro e comprimento, facilitando, assim, o manejo das mudas no viveiro, além de propiciar a seleção de plantas de qualidade e plantio no período chuvoso, possibilitando a obtenção de um pomar uniforme e vigoroso, além de promover a utilização de recipientes menores e, conseqüentemente, menor volume de substrato e demanda por área, reduzindo-se, assim ,o custo final da muda (PIO, 2002).

Outra alternativa na produção de mudas de figueira é a utilização de estacas oriundas da desbrota, que é realizada 30 a 60 dias após a realização da poda hibernal da figueira, sendo conservado apenas 1 a 2 brotos por haste, eliminando-se os demais (CHALFUN et al., 2002). Trabalho dessa natureza foi desenvolvido por Pio et al. (2004), os quais comprovaram que a presença de apenas duas folhas e ausência da gema apical nessas estacas oriundas da desbrota promovem enraizamento próximo a $90 \%$.

Por ser um método novo de propagação para a cultura da figueira, outros trabalhos devem ser desenvolvidos, visando à adequação e melhoria das mudas obtidas. Sendo assim, o substrato de enraizamento pode vir a promover melhorias e ganhos significativos. O substrato é um fator que afeta o enraizamento e desempenha papel importante, especialmente em espécies de difícil enraizamento. De acordo com Couvillon (1998), um substrato ideal é aquele que retém um teor de água suficiente para evitar a dessecação da base da estaca e, uma vez saturado, tem espaço poroso adequado para facilitar o enraizamento e evitar o desenvolvimento de doenças. O substrato apresenta um papel fundamental para 0 desenvolvimento das raízes das estacas, devendo possuir baixa densidade, boa capacidade de absorção e retenção de água, boa aeração e drenagem, para evitar o acúmulo de umidade, além de estar isento de pragas, doenças e substâncias tóxicas (KÄMPF, 2000; WEDLING et al., 2002).

Com o presente trabalho teve-se como objetivo verificar o enraizamento de estacas de figueira oriundas da desbrota, por meio da utilização de diferentes substratos.

\section{MATERIAL E MÉTODOS}

Foram coletadas estacas herbáceas de aproximadamente $10 \mathrm{~cm}$ de comprimento da figueira 'Roxo de valinhos', proveniente da coleção de fruteiras do Departamento de Produção Vegetal da Escola Superior de Agricultura "Luiz de Queiroz" Universidade de São Paulo (USP/ESALQ), no momento da desbrota da figueira (setembro). Foram conservadas apenas duas folhas na extremidade superior e removeuse a gema apical das estacas, segundo a metodologia de Pio et al. (2004). Após o preparo, as estacas foram acondicionadas individualmente em bandejas de polipropileno de 72 células (capacidade de $120 \mathrm{~cm}^{3}$ por célula), contendo diferentes substratos: casca de pinus ${ }^{\circledR}$, vermiculita $^{\circledR}$, fibra de coco $^{\circledR}$, plantmax ${ }^{\circledR}$, solo + esterco bovino $(1: 1 \mathrm{v} / \mathrm{v})$ e tropstrato ${ }^{\circledR}$. Posteriormente, foram transferidas para câmara de nebulização intermitente (temperatura de $25 \pm 5^{\circ} \mathrm{C}$, UR média de $72 \%$, tempo de aspersão de 20 segundos em intervalos de 10 minutos).

Os substratos em estudo foram analisados quanto às suas propriedades físicas, verificando-se o volume de massa, densidade aparente, porosidade de aeração (espaço de aeração), água disponível às plantas (espaço preenchido por água) e porosidade total (espaço poroso total), de acordo com a metodologia de Smith \& Pokorny (1977), no laboratório de análises físicas de substratos da USP/ESALQ.

O delineamento utilizado foi o inteiramente casualizado, contendo seis tratamentos (substratos), com quatro repetições e unidade experimental composta por dez estacas. Após 50 dias, foram coletados os seguintes dados biométricos: porcentagem de estacas enraizadas, porcentagem de estacas brotadas, porcentagem de estacas mortas, número de folhas e número de raízes emitidas da estaca.

Os dados foram submetidos à análise de variância e as médias, ao teste Scott-Knott (SCOTT \& KNOTT, 1974), ao nível de 5\% de probabilidade (GOMES, 2000). As análises foram realizadas pelo programa computacional Sistema para Análise de Variância - SISVAR (FERREIRA, 2000).

\section{RESULTADOS E DISCUSSÃO}

Verificou-se que, para a porcentagem de estacas enraizadas, os substratos fibra de $\operatorname{coco}^{\circledR}$ e plantmax ${ }^{\circledR}$ promoveram resultados superiores, em comparação aos demais substratos (86,87\% e 76,67\% de enraizamento, respectivamente) (Tabela 1). Os substratos citados anteriormente e ainda o substrato solo + esterco bovino 
PIO, R. et al.

$(1: 1 \mathrm{v} / \mathrm{v})$ proporcionaram menor porcentagem de estacas mortas. Para as características pertinentes à parte aérea das estacas (porcentagem de estacas brotadas e número de folhas), os substratos fibra de coco $^{\circledR}$, plantmax ${ }^{\circledR}$, solo + esterco bovino (1:1 v/v) e tropstrato ${ }^{\circledR}$ destacaram-se.

Porém, para o número de raízes emitidas da estaca, verificou-se que os substratos fibra de $\operatorname{coco}^{\circledR}$ e tropstrato ${ }^{\circledR}$ favoreceram cerca de 20,86 e 21,6 raízes por estaca, em média (Tabela 1). Por esses resultados, verifica-se um aumento de aproximadamente três raízes por estaca, em comparação ao trabalho desenvolvido por Pio et al. (2004), que conseguiram cerca de 18 raízes por estaca, porém, utilizando o substrato areia + solo $(2: 1 \mathrm{v} / \mathrm{v})$.

Em geral, os substratos fibra de $\operatorname{coco}^{\circledR} \mathrm{e}$ plantmax ${ }^{\circledR}$ favoreceram melhores resultados. Essa superioridade pode ser explicada pelas características físicas desses substratos (Tabela 2). Verificou-se que esses dois substratos apresentaram maior porosidade de aeração (49,70\% e 46,50\%, respectivamente). Conseqüentemente, os substratos que promoveram resultados inferiores para todas as características analisadas neste trabalho (casca de pinus ${ }^{\circledR}$ e vermiculita ${ }^{\circledR}$ ) tiveram, segundo a análise física (Tabela 2), resultados inferiores para a porosidade de aeração (13,81\% e 32,70\%, respectivamente). Boa aeração é uma das características físicas importantes para o crescimento de plantas em recipientes (BEARDSELL et al., 1979). Não somente a água é necessária para as plantas, mas também o ar é importante para o crescimento radicular (VERDONCK et al., 1981). Sendo assim, verifica-se a importância da escolha correta do substrato a ser utilizado. Um bom substrato para a produção de mudas frutíferas deve proporcionar retenção de água suficiente e, quando saturado (em excesso de água), deve manter quantidades adequadas de espaço poroso para facilitar o fornecimento de oxigênio, indispensável no processo de propagação (SMIDERLE \& MINAMI, 2001). O substrato no enraizamento de estacas desempenha importante função, principalmente para as espécies que possuem dificuldades em emitirem raízes. Um substrato ideal é aquele que, além de servir de suporte para a sustentação da estaca, retém água fornecida via irrigação por um longo período de tempo e fornece ambiente escuro e aeração para a base da estaca, que certamente irá influir sobre a porcentagem de enraizamento, bem como sobre o tipo de raízes formadas (HOFFMANN et al., 1996).

Os melhores substratos devem apresentar, entre outras importantes características, ausência de patógenos, plantas daninhas, riqueza em nutrientes essenciais, textura e estrutura adequadas (ANTUNES et al., 2002; SILVA et al., 2001). Pasqual et al. (2001) afirmam que o substrato é um dos fatores de maior importância no enraizamento de estacas.

Após a finalização do experimento, 60 estacas enraizadas foram transplantadas para sacos plásticos de dimensões de 20 x $14 \mathrm{~cm}$, preenchidos com substrato plantmax $^{\circledR}$ e colocadas em telado constituído por sombrite $50 \%$ de luminosidade. Após 30 dias do tranplantio, verificou-se que $84 \%$ das estacas permaneceram vivas e, após 60 dias, algumas mudas já estavam aptas para serem levadas ao campo, como mostrado na Figura 1.

TABELA 1 - Diferentes substratos na porcentagem de estacas enraizadas (PEE), porcentagem de estacas brotadas (PEB), porcentagem de estacas mortas (PEM), número de folhas (NF) e número de raízes emitidas (NRE) de estacas herbáceas de figueira oriundas da desbrota. USP/ESALQ, Piracicaba-SP, 2003.

\begin{tabular}{lccccc}
\hline \multirow{2}{*}{ Substratos } & \multicolumn{5}{c}{ Variável analisada* } \\
\cline { 2 - 6 } & PEE & PEB & PEM & NF & NRE \\
\hline Casca de Pinus $^{\circledR}$ & $33,34 \mathrm{c}$ & $13,34 \mathrm{~b}$ & $60,00 \mathrm{~b}$ & $0,00 \mathrm{~b}$ & 7,84 c \\
Vermiculita $^{\circledR}$ & $16,67 \mathrm{~d}$ & $6,67 \mathrm{~b}$ & $73,34 \mathrm{~b}$ & $0,67 \mathrm{~b}$ & $8,17 \mathrm{c}$ \\
Fibra de coco $^{\circledR}$ & $86,87 \mathrm{a}$ & $43,34 \mathrm{a}$ & $10,00 \mathrm{a}$ & $1,67 \mathrm{a}$ & $20,86 \mathrm{a}$ \\
Plantmax $^{\circledR}$ & $76,67 \mathrm{a}$ & $56,67 \mathrm{a}$ & $20,00 \mathrm{a}$ & $1,34 \mathrm{a}$ & $18,10 \mathrm{~b}$ \\
Solo + Esterco $^{(1: 1 \mathrm{v} / \mathrm{v})}$ & $63,34 \mathrm{~b}$ & $53,34 \mathrm{a}$ & $26,67 \mathrm{a}$ & $1,34 \mathrm{a}$ & $14,94 \mathrm{~b}$ \\
Tropstrato $^{\circledR}$ & $55,00 \mathrm{~b}$ & $50,00 \mathrm{a}$ & $45,00 \mathrm{~b}$ & $1,44 \mathrm{a}$ & $21,60 \mathrm{a}$ \\
cv (\%) & 15,26 & 15,09 & 34,59 & 27,50 & 13,06 \\
\hline
\end{tabular}

* Médias seguidas da mesma letra na coluna não diferem significamente entre si pelo teste Scott-Knott ao nível de $5 \%$ de probabilidade.

Ciênc. agrotec., Lavras, v. 29, n. 3, p. 604-609, maio/jun., 2005 
TABELA 2 - Análise física dos substratos, de acordo com a metodologia de Smith \& Pokorny (1977). ESALQ/USP, Piracicaba-SP, 2003.

\begin{tabular}{lccccc}
\hline \multicolumn{1}{c}{ Substratos } & $\begin{array}{c}\text { Volume } \\
\mathbf{( g / 1 0 0} \\
\mathbf{m L})\end{array}$ & $\begin{array}{c}\text { Densidade } \\
\text { Aparente } \\
\mathbf{( g / m L )}\end{array}$ & $\begin{array}{c}\text { Porosidade de } \\
\text { Aeração (\%) }\end{array}$ & $\begin{array}{c}\text { Espaço } \\
\text { preenchido por } \\
\text { água (\%) }\end{array}$ & $\begin{array}{c}\text { Espaço } \\
\text { poroso total } \\
\mathbf{( \% )}\end{array}$ \\
\hline Casca de Pinus $^{\circledR}$ & 51,24 & 0,24 & 13,81 & 11,72 & 25,53 \\
Vermiculita $^{\circledR}$ & 46,42 & 0,15 & 32,70 & 48,10 & 80,77 \\
Fibra de coco $^{\circledR}$ & 54,26 & 0,10 & 49,70 & 19,58 & 69,27 \\
Plantmax $^{\circledR}$ & 39,20 & 0,42 & 46,50 & 53,71 & 70,10 \\
Solo $^{\circledR}$ Esterco $(1: 1 \mathrm{v} / \mathrm{v})$ & 46,42 & 0,67 & 43,17 & 30,38 & 73,55 \\
Tropstrato $^{\circledR}$ & 4843 & 0,31 & 35,17 & 35,45 & 70,29 \\
\hline
\end{tabular}

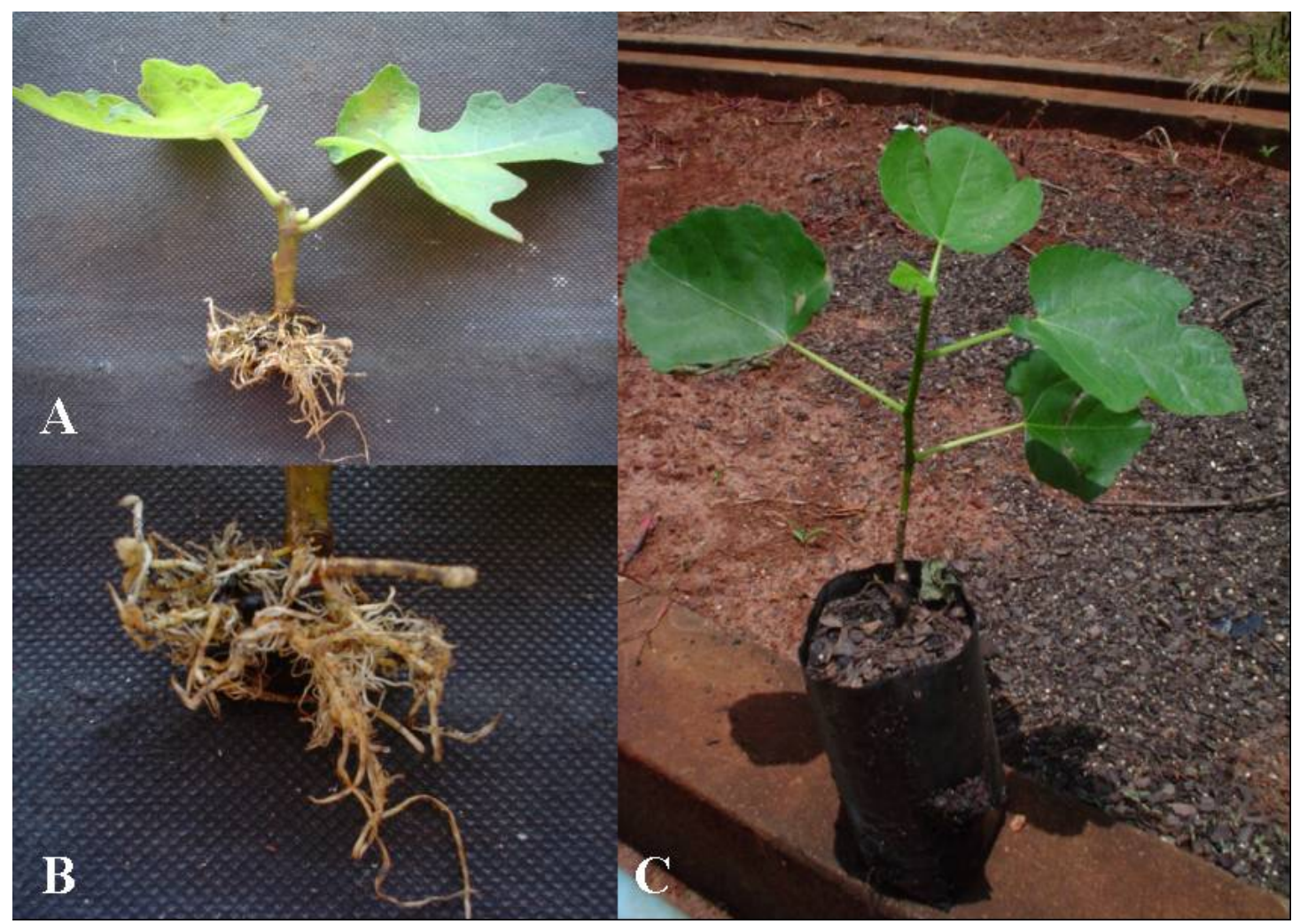

FIGURA 1 - Estaca herbácea de figueira oriunda da desbrota enraizada (A); Detalhe do sistema radicular formado na estaca; Planta de figueira oriunda de estaca herbácea após três meses do transplante, pronta para ser levada ao campo (C). ESALQ/USP, Piracicaba-SP, 2003. 
PIO, R. et al.

\section{CONCLUSÃO}

Os substratos fibra de coco $^{\circledR}$ e plantmax ${ }^{\circledR}$ são os recomendados na propagação de estacas herbáceas de figueira oriundas da desbrota.

\section{REFERÊNCIAS BIBLIOGRÁFICAS}

ANTUNES, L. E. C.; DUARTE FILHO, J.; BUENO, S. C. S.; MINAMI, K. Tratamento de substratos na produção de mudas de plantas frutíferas. Informe Agropecuário, Belo Horizonte, v. 23, n. 216, p. 16-20, 2002.

ANUÁRIO de informações estatísticas da agricultura. São Paulo: IEA, 2002. 265 p.

BEARDSELL, D. V.; NICHOLS, D. G.; JONES, D. L. Physical properfies of nursery potting-mixtures. Scientia Horticulturae, Amsterdam, v. 11, p. 1-8, 1979.

CHALFUN, N. N. J.; ABRAHÃO, E.; ALVARENGA, A. A.; REGINA, M. A.; PIO, R. Poda e condução da figueira. Lavras: UFLA, 2002. 12 p. (Boletim técnico, 104).

CHALFUN, N. N. J.; HOFFMANN, A. Propagação da figueira. Informe Agropecuário, Belo Horizonte, v. 18, n. 188, p. 9-13, 1997.

CHALFUN, N. N. J.; PASQUAL, M.; HOFFMANN, A. Fruticultura comercial: frutíferas de clima temperado. Lavras: UFLA/FAEPE, 1997. 304 p.

COELHO, G. V. de A.; CHALFUN, N. N. J.; MIRANDA, C. S. de; VEIGA, R. D.; GONÇALVES, F. C. Efeito da época de poda da cinamida hidrogenada e da cobertura de solo na produção antecipada de fìgo verde da cultivar Roxo de valinhos. In: CONGRESSO BRASILEIRO DE FRUTICULTURA, 17., 2002, Belém. Anais... Belém: SBF, 2002. CD-ROM.

COUVILLON, G. A. Rooting responses to different treatments. Acta Horticulturae, Wageningen, v. 227, p. 187-196, 1998.

FERREIRA, D. F. Análise estatística por meio do SISVAR (Sistema para Análise de Variância) para Windows versão 4.0. In: REUNIÃO ANUAL DA REGIÃO BRASILEIRA DA SOCIEDADE INTERNACIONAL DE BIOMETRIA, 45., 2000, São Carlos. Anais... São Carlos: UFSCar, 2000. p. 255-258.

GOMES, F. P. Curso de estatística experimental. 14. ed. Piracicaba: USP/ESALQ, 2000. 477 p.
GONÇALVES, F. C. Formas de acondicionamento a frio de estacas e mudas de figueira (Ficus carica $\mathbf{L}$.). 2002. 84 p. Dissertação (Mestrado em Agronomia) Universidade Federal de Lavras, Lavras, 2002.

HOFFMANN, A.; CHALFUN, N. N. J.; ANTUNES, L. E. C.; RAMOS, J. D.; PASQUAL, M.; SILVA, C. R. de R. e. Fruticultura comercial: propagação de plantas frutíferas. Lavras: UFLA/FAEPE, 1996. 319 p.

KÄMPF, A. N. Produção comercial de plantas ornamentais. Guaíba: Agropecuária, 2000. 254 p.

PASQUAL, M.; CHALFUN, N. N. J.; RAMOS, J. D.; VALE, M. R. do; SILVA, C. R. de R. e. Fruticultura comercial: propagação de plantas frutíferas. Lavras: UFLA/FAEPE, 2001. 137 p.

PENTEADO, S. R. O cultivo da figueira no Brasil e no mundo. In: CORRÊA, L. S. de; BOLIANI, A. C. (Eds.). Cultura da figueira: do plantio à comercialização. Ilha Solteira: FAPESP, 1999. p. 1-16.

PIO, R. Ácido indolbutírico e sacarose no enraizamento de estacas apicais e desenvolvimento inicial da figueira (Ficus carica L.). 2002. 109 p. Dissertação (Mestrado em Agronomia) - Universidade Federal de Lavras, Lavras, 2002.

PIO, R.; CHALFUN, N. N. J.; RAMOS, J. D.; GONTIJO, T. C. A.; TOLEDO, M.; CARRIJO, E. P. Presença de folhas e gema apical no enraizamento adventício de estacas herbáceas de figueira oriundas da desbrota. Revista Brasileira de Agrociência, Pelotas, v. 10, n. 1, p. 1-4, 2004.

SCOTT, A. J.; KNOTT, M. A cluster analysis method for grouping means in the analysis of variance. Biometrics, Washington, v. 30, p. 507-512, Sept. 1974.

SILVA, R. P. da; PEIXOTO, J. R.; JUNQUEIRA, N. T. $\mathrm{V}$. Influência de diversos substratos no desenvolvimento de mudas de maracujazeiro azedo (Passiflora edulis Sims f. flavicarpa DEG). Revista Brasileira de Fruticultura, Jaboticabal, v. 23, n. 2, p. 377-381, 2001.

SMIDERLE, O. S.; MINAMI, K. Emergência e vigor de plântulas de goiabeira em diferentes substratos. Revista Científica Rural, Bagé, v. 6, n. 1, p. 38-45, 2001. 
SMITH, R. C.; POKORNY, F. A physical Acta Horticulturae, Wageningen, n. 126, p. 251-258, characterization of some potting substrates in 1981.

commercial nurseries. [S.l.: s.n.], 1977. 8 p.

WEDLING, I.; GATTO, A.; PAIVA, H. N. Substratos, VERDONCK, O.; VLEESCHAUWER, D.; BOODT, adubação e irrigação na produção de mudas. Viçosa: M. de. The influence of the substrate to plant growth. Aprenda Fácil, 2002. 166 p. 